\title{
MULTI-SCALE EFFECT ON LANDSCAPE PATTERN ANALYSIS USING SATELLITE DATA WITH A RANGE OF SPATIAL RESOLUTIONS
}

\author{
Yi ZHAO $^{1)}$, MizUKI TOMITA ${ }^{2)}$, IPPEI HARADA ${ }^{2)}$, KeITAROU HARA $^{2)}$ \\ ${ }^{1)}$ Graduate school of informatics, Tokyo University of Information Sciences, 4-1Onaridai, \\ Wakaba-ku, Chiba 265-8501, Japan, e-mail: h09003oc@edu.tuis.ac.jp, Phone: +81-43- \\ 236-4622 \\ ${ }^{2)}$ Department of Environmental Information, Faculty of Informatics, Tokyo University of \\ Information Sciences
}

Received: $5^{\text {th }}$ September 2010, Accepted: $10^{\text {th }}$ August 2011

\begin{abstract}
In recent years, identifying the relationship between pattern and scale has emerged as a central issue in ecology and geography. Scale has been defined by grain or resolution but bias in results will occur if the scale is wrongly selected relevant to the landscape evaluation. In this research, satellite data of varying resolution, QuickBird $(2.5 \mathrm{~m})$, ALOS/AVNIR-2 (10m), Terra/ASTER (15m) and Landsat/ETM+ $(30 \mathrm{~m})$, were employed to analyze the scale effects of grain size. The research was implemented at Azeta, a typical rural landscape located in Sakura City, central Japan. Land-cover classifications were first implemented using the Maximum Likelihood Method on satellite data of varying resolution. Based on the results of these classifications, a number of landscape metrics imbedded in the FRAGSTATS were extracted for landscape pattern analysis. The results indicate that most landscape patterns show some degree of consistency and scaling relations such as power-law among the various satellite resolutions. The applicability of these various satellite data resolutions for landscape analysis in the target area was also evaluated.
\end{abstract}

Keywords: LULC classification, extrapolability, landscape metrics, scale effect

\section{INTRODUCTION}

Relations of pattern and scale are central issues in ecology, unifying population biology and ecosystems science, and basic and applied ecology (Levin 1992). Ecological problems often require extrapolation of fine-scale measurements for the analysis of broad-scale phenomena. It is also believed that spatial characteristics could be transferred across scales under specific conditions (Allen and Thomas 1982). It is thus required to shed light on how the spatial information is transferred from a fine scale to a broader scale, and how it supports and complements the transformation as previous knowledge. While the term "scale" here may refer to several definitions, including grain (or resolution), extent, coverage, spacing, and cartographic scale (Wu 2006), the analysis in this paper will only focus on "grain" (the spatial resolution of a particular satellite sensor). 
LULC patterns are regarded as important factors in the ecosystem function, and can be considered to represent a spatial aspect of a specific area as determined by both, geographical and biological conditions (Bain and Brush 2004). Therefore, evaluation of landscape patterns based on a multi-scale perspective will provide useful insights for regional conservation, such as how to minimize loss and fragmentation of wildlife habitat due to rapid, widespread human-induced LULC changes. In recent years, remote sensing has become an effective tool to understand LULC characteristics in a variety of scales. This trend is evident in the increased number of research studies related to the issue (Turner et al 1989a; Benson and MacKenzie 1995; Moody and Woodcock 1995; Wu 2004; Zhu et al 2006; Saura 2004; Neel et al 2004; Liu and Weng 2009). Nevertheless, landscape pattern analysis may produce different results when satellite sensors of varied scale are utilized. Recently it has become clear that understanding of the scaling relation among different satellite data can prove useful in producing more efficient land-surface observation based on remote sensing (Quattrochi and GoodChild 1997). Although much work has been done to examine the scaling effect, research on the scaling relations of various satellite sensor with different spatial resolution is still lacking. The major goals of this study are to understand how landscape characteristics respond to changing scale (grain size) and to clarify the inherent scaling relations, such as power-law as found by $\mathrm{Wu}(2000 ; 2004)$, among the various satellite resolutions.

\section{STUDY AREA}

This research employs data from a approximately 309 ha area in Azeta $\left(35^{\circ} 42^{\prime} \mathrm{N}\right.$, $\left.140^{\circ} 10^{\prime} \mathrm{E}\right)$ located in the northwest part of Sakura city in Chiba Prefecture, on the eastern outskirts of Tokyo in central Japan (Fig.1). The area features a typical Japanese rural landscape known as "Yatsu Valley", which consists of narrow, highly-branched valleys cut into level, plateau-like uplands. The area has been selected as a vital habitat for conserving the regional natural environment, and has been designated as a natural park. Although the area is surrounded by densely populated residential zones, the quality of the natural habitats is still high and the area functions as a space where nature can coexist with urban lifestyles. Various wildlife, including species listed as endangered by Chiba Prefecture, inhabit the area. These include the grey-faced buzzard eagle (Butastur indicus) and Japanese brown frog (Rana japonica) as well as plants such as Ricciocarpos natans, Azolla japonica, Ottelia japonica, and Penthorum chinense (Sakura 2006). In recent years, 'Satoyama', as Japanese rural landscapes are known, have been decreasing in area due to such factors as rapid urbanization in some areas, as well as farmland abandonment due to loss of young people from the agricultural sector in others. Conservation of Satoyama landscapes, including the Yatsu Valley environments such as represented by Azeta, is thus now becoming a very important issue in conservation of biological and cultural diversity (Takeuchi et al 2003). 
Fig. 1: Study area: Azeta, Sakura city, Chiba prefecture.

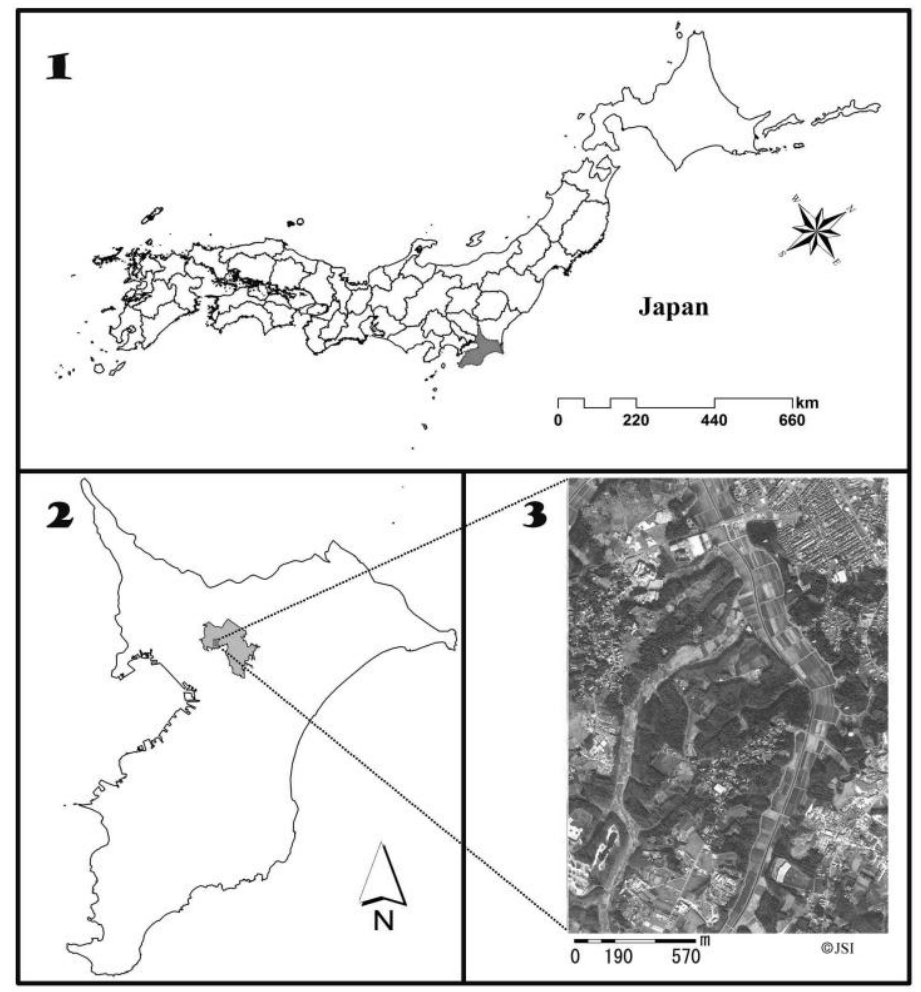

\section{MATERIALS AND METHODS}

\section{Data preparation}

To reveal the scale effect of varying resolution satellite data, images from QuickBird, ALOS/AVNIR-2, Terra/ASTER and Landsat/ETM+ were employed in the analysis. Detailed characteristics of each satellite data are summarized in Table 1. All of the images except for the image from ALOS/AVNIR-2, are in the same area, and have been pre-geocorrected by the providers. The ALOS/AVNIR-2 was geo-corrected to the Universal Transverse Mercator (UTM) projection with WGS 1984 Zone 54, by referencing the image of QuickBird due to its high visibility. 20 ground control points were chosen for the image. The root mean square errors (RMSEs) for the geo-correction were less than 1 pixel. An additional visually interpreted aerial photograph taken in 2008 of the same area was also utilized as reference data for the LULC classification and accuracy assessment. 
Table 1: Detailed descriptions of each four different satellite sensors used for the analysis.

\begin{tabular}{lcccc}
\hline & QuickBird & ALOS/AVNIR-2 & Terra/ASTER & Landsat/ETM+ \\
\hline Swath Width & $16.5 \mathrm{~km}^{2}$ & $70 \mathrm{~km}^{2}$ & $60 \mathrm{~km}^{2}$ & $185 \mathrm{~km}^{2}$ \\
Recurrence Period & $1 \sim 3.5$ days & 46 days & 16 days & 16 days \\
Resolution & $2.5 \mathrm{~m}$ & $10 \mathrm{~m}$ & $15 \mathrm{~m}$ & $30 \mathrm{~m}$ \\
Observation Date & $2009 / 1 / 9$ & $2007 / 11 / 15$ & $2008 / 1 / 8$ & $2006 / 11 / 3$ \\
Price & $25.2 € / 1 \mathrm{~km}^{2}$ & $3.2 \sim 6.4 € / 1 \mathrm{~km}^{2}$ & $1.7 € / 1 \mathrm{~km}^{2}$ & Free \\
Spectral Bands & B1: $45-0.52 \mu \mathrm{m}$ & B1: $0.45-0.50 \mu \mathrm{m}$ & B1: $0.52-0.60 \mu \mathrm{m}$ & B1: $.45-0.52 \mu \mathrm{m}$ \\
& B2: $0.52-0.60 \mu \mathrm{m}$ & B2: $0.52-0.60 \mu \mathrm{m}$ & B2: $0.63-0.69 \mu \mathrm{m}$ & B2: $0.52-0.60 \mu \mathrm{m}$ \\
& B3: $0.63-0.69 \mu \mathrm{m}$ & B3: $0.61-0.69 \mu \mathrm{m}$ & B3: $0.78-0.86 \mu \mathrm{m}$ & B3: $0.61-0.69 \mu \mathrm{m}$ \\
& B4: $0.76-0.90 \mu \mathrm{m}$ & B4: $0.76-0.89 \mu \mathrm{m}$ & & B4: $0.76-0.90 \mu \mathrm{m}$ \\
& & & & B5: $1.55-1.75 \mu \mathrm{m}$ \\
& & & & B7: $2.08-2.35 \mu \mathrm{m}$ \\
\hline
\end{tabular}

\section{LULC classification}

An image from each sensor was first used to identify six LULC types for the study area based on the ground real data. The classes are: Forest, Grass, Dry Farmland, Paddy Field, Urban Area, and Water Area. Because of absorption in the near-infrared spectrum, the nearinfrared spectral band of each satellite imagery was used separately to identify water bodies. In order to avoid misclassification, each image was then subdivided into vegetated area and non-vegetated area according to the normalized difference vegetation index (NDVI). To distinguish vegetated from non-vegetated areas, the original values of NDVI between -1 and 1 were converted into 8-bit unsigned thematic (range 0-255) data. LULC classification was implemented separately for each generated vegetated and non-vegetated area data by using the supervised method of Maximum Likelihood. These analyses were performed using ERDAS IMAGINE 9.3 (Leica Geosystems GIS \& Mapping, LLC).

\section{Multi-scale landscape analysis}

To investigate the effects of changing scale (grain size), the spatial resolution of four LULC classification maps from each satellite image were systematically changed from their original pixel size to 100 meter at intervals of 5 meters, keeping the spatial extent constant. As the grain size increased, a series of coarser resolution maps were created through a majority rule, which is one of the most commonly used methods for aggregating categorical data in ecology and remote sensing (Turner et al 1989a; Wu 2004; Saura 2004;). Based on these aggregated categorical data, twenty two class-level landscape metrics imbedded in FRAGSTATS 3.3 (McGarigal et al 2002) were employed for landscape analysis. These were: PLAND (Percentage of Landscape), NP (Number of Patches), PD (Patch Density), LPI (Largest Patch Index), TE (Total Edge), ED (Edge Density), LSI (Landscape Shape Index), AREA_MN (Mean Patch Size), GYRATE_MN (Mean Radius of Gyration Distribution), SHAPE_MN (Mean Patch Shape), PARA_MN (Mean Perimeter-Area Ratio), FRAC_MN (Mean Fractal Dimension Index), CIRCLE_MN (Mean Related Circumscribing Circle), CONTIG_MN (Mean Contiguity Index), PAFRAC(Perimeter-Area Fractal Dimension), TCA (Total Core Area), NDCA (Number of Disjunct Core Areas), PROX_AM (Area-weighted Mean of Proximity Index Distribution), ENN_MN (Mean Euclidean Nearest Neighbor Distance), IJI (Interspersion \& Juxtaposition Index), AI 
(Aggregation Index), COHESION (Patch Cohesion Index). These metrics are often utilized in other research studies for purposes such as examining landscape fragmentation and connectivity (Fahrig and Merriam 1985; Riitters et al 2000; Tischendorf 2001; McAlpine and Eyre 2002; Leitão et al 2006).

\section{RESULTS}

\section{Accuracy assessment}

The overall accuracies of the classification for each of the four satellite images on their original spatial resolution were $77.23 \%, 78.84 \%, 81.20 \%$ and $83.63 \%$ (Table 2). The kappa statistics for the images were respectively $0.732,0.735,0.749$ and 0.749 . Although these results show that all of the images were accurately classified, the values increase as the spatial resolution of the satellite becomes coarser. This increase occurs because the socalled 'salt and pepper effect' decreases as image resolution becomes coarser, pulling the classification results closer to the reference data. Grass, Dry Farm Land and Irrigated Paddy Field showed lower accuracies compared to Forest and Urban Area due to their close spectral separability, which caused some difficulties in classification of each satellite data. In addition, the accuracy of the Water Area classifications also performed well with all satellites except Terra/ASTER, but dropped as the spatial resolution of the satellite data become coarser.

Table 2: Accuracy assessment report of LULC classification for each satellite data. Fr: Forest, Gr: Grass, DFL: Dry Farm Land, PF: Paddy Field, UA: Urban Area, WA: Water Area.

\begin{tabular}{|c|c|c|c|c|c|c|c|c|c|}
\hline & & $\mathrm{Fr}$ & $\mathrm{Gr}$ & DFL & $\mathrm{PF}$ & $\mathrm{UA}$ & WA & $\begin{array}{l}\text { Overall } \\
\text { Acc(\%) }\end{array}$ & $\begin{array}{l}\text { Overall } \\
\text { Kappa }\end{array}$ \\
\hline \multirow{3}{*}{ QuickBird } & $\begin{array}{l}\text { Producer's } \\
\text { acc }(\%)\end{array}$ & 98.40 & 82.80 & 63.60 & 86.10 & 89.70 & 42.8 & \multirow{3}{*}{77.23} & \multirow{3}{*}{0.732} \\
\hline & $\begin{array}{l}\text { User's acc } \\
(\%)\end{array}$ & 93.98 & 75.27 & 80.30 & 78.42 & 93.15 & 100.00 & & \\
\hline & $\begin{array}{l}\text { Kappa (x) } \\
\text { Statistics }\end{array}$ & 0.928 & 0.703 & 0.764 & 0.741 & 0.918 & 1.000 & & \\
\hline \multirow{3}{*}{ AVNIR-2 } & $\begin{array}{l}\text { Producer's } \\
\text { acc }(\%)\end{array}$ & 98.60 & 70.75 & $55.78 \%$ & 67.18 & 98.70 & 69.49 & \multirow{3}{*}{78.84} & \multirow{3}{*}{0.735} \\
\hline & $\begin{array}{l}\text { User's acc } \\
(\%)\end{array}$ & 88.19 & 49.10 & 75.55 & 75.57 & 91.13 & 93.18 & & \\
\hline & $\begin{array}{l}\text { Kappa (x) } \\
\text { Statistics }\end{array}$ & 0.847 & 0.436 & 0.684 & 0.685 & 0.887 & 0.931 & & \\
\hline \multirow{3}{*}{ ASTER } & $\begin{array}{l}\text { Producer's } \\
\text { acc }(\%)\end{array}$ & 97.50 & 80.18 & 51.18 & 70.42 & 92.21 & 21.21 & \multirow{3}{*}{81.20} & \multirow{3}{*}{0.749} \\
\hline & $\begin{array}{l}\text { User's acc } \\
(\%)\end{array}$ & 85.00 & 58.19 & 76.11 & 80.29 & 92.61 & 50.00 & & \\
\hline & $\begin{array}{l}\text { Kappa (x) } \\
\text { Statistics }\end{array}$ & 0.759 & 0.549 & 0.710 & 0.759 & 0.911 & 0.494 & & \\
\hline \multirow{3}{*}{ ETM+ } & $\begin{array}{l}\text { Producer's } \\
\text { acc }(\%)\end{array}$ & 97.71 & 48.44 & 50.65 & 69.94 & 94.61 & 37.50 & \multirow{3}{*}{83.63} & \multirow{3}{*}{0.749} \\
\hline & $\begin{array}{l}\text { User's acc } \\
(\%)\end{array}$ & 89.64 & 73.81 & 64.46 & 88.97 & 80.61 & 75.00 & & \\
\hline & $\begin{array}{l}\text { Kappa (k) } \\
\text { Statistics }\end{array}$ & 0.772 & 0.723 & 0.586 & 0.838 & 0.774 & 0.747 & & \\
\hline
\end{tabular}




\section{LULC classification}

The classification results showed that Forest is the largest LULC type in the target area, and as mostly surrounded by the Urban Area (Fig.2). Apparently, the most elongated valley areas were covered by agricultural land-use type such as Paddy Field and Dry Farm Land. Although these areas still remained agriculture land, Grass area has increased obviously due to the rapid farming abandonment. These results also show that the areas of different LULC types are distributed sparsely in a typical mosaic pattern.

Fig. 2: Results of LULC classifications for each satellite sensor.
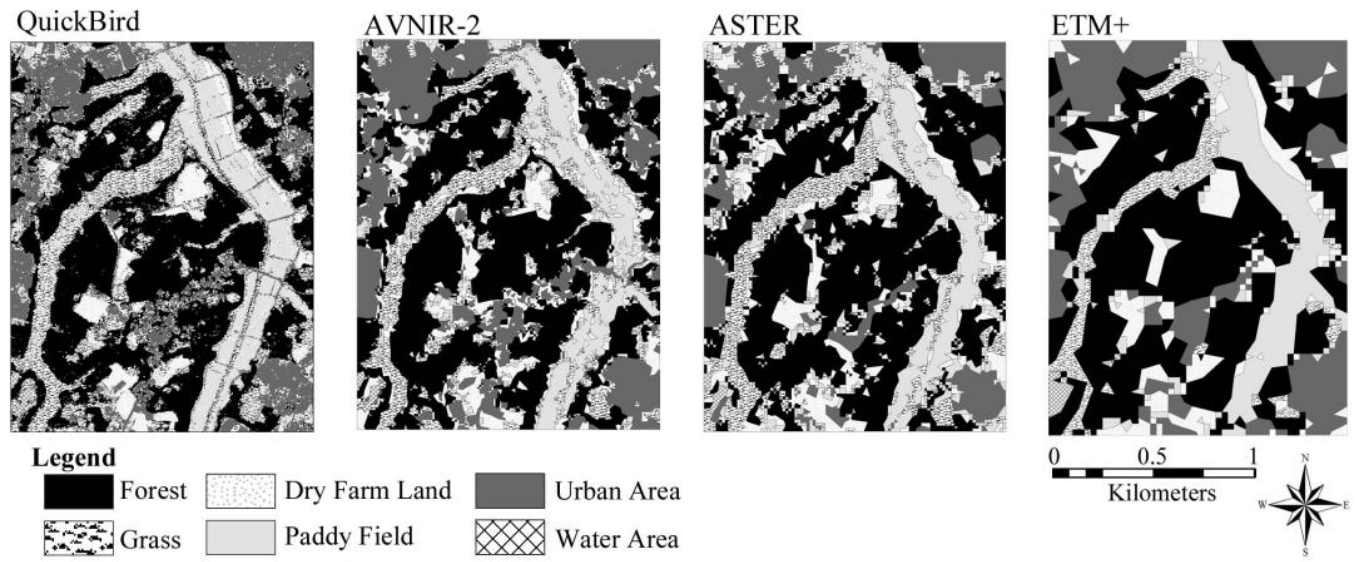

\section{Scaling relations with respect to changing scales (grain size)}

Figure 3 shows examples of how different metrics responded to changing grain size for each of the four satellite sensors in the form of scalograms, i.e., plots of landscape metrics against scale (grain size). Due to space limitation, all 22 metrics are not shown in Figure 3. As a resultstronger scaling effect showed in high resolution QuickBird, whereas the effect is less distinctive at a coarser grain size. Nevertheless, most of the metrics responded in a somewhat similar scaling pattern, with the value decreasing as the resolution became coarser. Also, because of mathematical similarity, some metrics such as NP and PD, TE, ED, LSI and PARA_MN exhibited an identical scaling relation.

With changing grain size through spatial aggregation, the responses of the 22 class-level metrics were then divided into four scaling relations; (1) Power-law $\left(y=a x^{b}\right)$, (2) Linear function $(y=a x+b)$, (3) Logarithmic function $(y=a \ln x+b)$, (4) Exponential function $\left(y=a^{x}\right)$. All results of these scaling relations between the four satellite sensors are summarized in Table 3, and power-law is considered to be the main scaling relation among the all metrics. The coefficient of determination $\left(R^{2}\right)$ was employed to examine the fitness of each scaling function for each satellite data. As a result, it is evident that power-law is the main scaling relation in case of grain size changing among different satellites. With the spatial resolution of the satellite data increasing, more than one scaling relation emerged to fit the datasets, and the relations became weaker as the value of $R^{2}$ become lower. This also means that extrapolability was degraded as the spatial resolution of satellite became coarser.

Based on the above results, the responses of these metrics were further divided into four general groups: metrics showing both consistent and robust scaling relations (Type I) which 
include 9 indices (NP, PD, TE, ED, LSI, AREA_MN, PARA_MN, ENN_MN, and PROX_AM); metrics showing consistent but less robust scaling relations (Type II) which include 4 indices (PLAND, IJI, COHESION and AI); and metrics showing staircase-like response with change scale (Type III) which include only 2 indices (TCA and NDCA). The rest of the metrics showed an unpredictable scaling behavior (Type IV). Please note that the term "consistent" here refers to the consistence of scaling relations in any forms of linear, power, or logarithmic functions between different satellite sensors, whereas "robust" implies the similarity of scaling relations between different LULC types within the same sensor.

Fig. 3: Examples of landscape metric scalograms with changing grain size

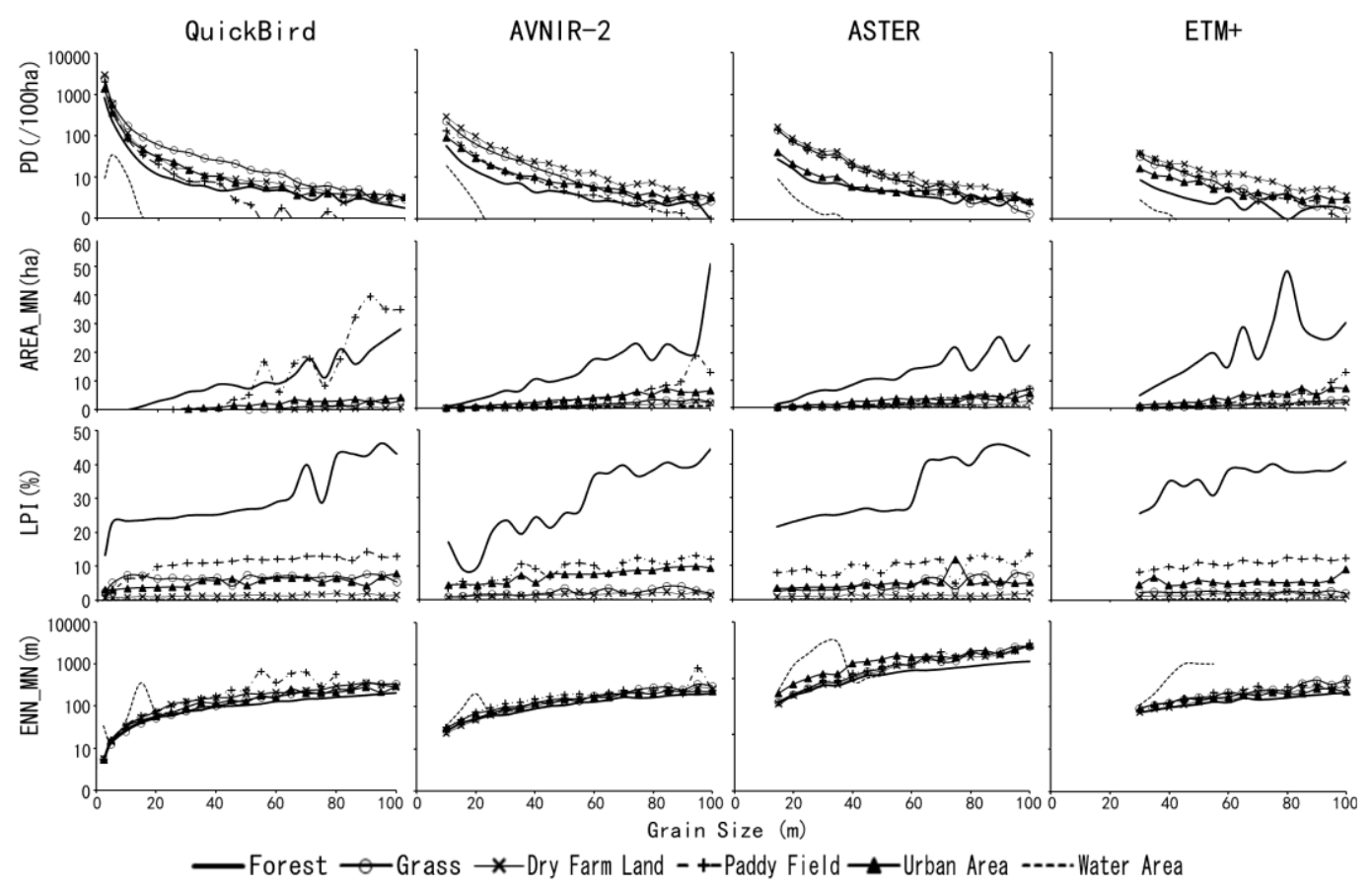


Table 3: Comparison of scaling relations of class-level metrics among different satellite sensors.

\begin{tabular}{|c|c|c|c|c|}
\hline landscape metrics & QuickBird & AVNIR-2 & ASTER & ETM+ \\
\hline PLAND & unpredictable & unpredictable & unpredictable & unpredictable \\
\hline NP & power law & power law & power law & logarithmic \\
\hline PD & power law & power law & power law & logarithmic \\
\hline LPI & unpredictable & unpredictable & unpredictable & unpredictable \\
\hline TE & power law & $\begin{array}{l}\text { logarithmic or } \\
\text { power law }\end{array}$ & $\begin{array}{l}\text { logarithmic or } \\
\text { power law }\end{array}$ & $\begin{array}{c}\text { logarithmic or } \\
\text { power law }\end{array}$ \\
\hline ED & logarithmic & logarithmic & logarithmic & logarithmic \\
\hline LSI & power law & logarithmic & logarithmic & logarithmic \\
\hline AREA_MN & power law & power law & power law & power law \\
\hline GYRATE_MN & power law & power law & power law & power law \\
\hline SHAPE_MN & unpredictable & unpredictable & unpredictable & unpredictable \\
\hline PARA_MN & power law & power law & power law & power law \\
\hline FRAC_MN & unpredictable & unpredictable & unpredictable & unpredictable \\
\hline CIRCLE_MN & unpredictable & unpredictable & unpredictable & unpredictable \\
\hline CONTIG_MN & unpredictable & unpredictable & unpredictable & unpredictable \\
\hline PAFRAC & unpredictable & unpredictable & unpredictable & unpredictable \\
\hline TCA & staircase & staircase & staircase & staircase \\
\hline NDCA & staircase & staircase & staircase & staircase \\
\hline PROX_AM & power law & power law & exponential & $\begin{array}{c}\text { exponential or } \\
\text { power law }\end{array}$ \\
\hline ENN_MN & power law & power law & power law & power law \\
\hline IJI & unpredictable & unpredictable & unpredictable & unpredictable \\
\hline AI & unpredictable & unpredictable & unpredictable & unpredictable \\
\hline COHESION & unpredictable & unpredictable & unpredictable & unpredictable \\
\hline
\end{tabular}

Note: “*” indicates low fitness of determination coefficient $\left(R^{2}\right)$. The term unpredictable here indicates that the value of $R^{2}$ is lower than 0.3 . 


\section{DISCUSSION}

The results showed that the classification from each of the four selected satellite sensor was acceptable. Obviously, satellite data with higher resolution could more delicately reflect landscape characteristics such as patch shape, and distribution status such as canopy gap.

The results of multi-scale landscape analysis showed that more than half of the landscape metrics have significant scaling effects with changing grain size and are predictable across the scale. These metrics may be effective for specific purposes, such as detecting landscape fragmentation or connectivity due to their robust and consistent behavior against satellite data with various spatial resolutions (Saura 2004). In contrast, half of the metrics, including PLAND, LPI, SHAPE_MN, FRAC_MN, CIRCLE_MN, CONTIG_MN, PAFRAC, IJI, COHESION, and AI are independent on grain size and are thus unpredictable across scales in any satellite data. This indicates that a more complex relationship, such as polynomial function or nonlinear relation, may exist between the metrics and scales. From the results of comparison of various satellite sensors, it is evident that power-law is the main and consistent scaling relation among all the landscape metrics which is consistent with previous studies (Wu et al 2000; Wu 2004). This deepens our understanding of hierarchical structure in landscape which follows power laws as in biological and ecological systems (Brown et al 2000; Schneider 2001). The stronger scale effect on satellites with higher resolution indicates that their landscape metrics are highly dependent on the scale and that these satellites have good information extra polability. This may provide a useful insight, that datasets with finer scales of resolution are more appropriate for making an extrapolation from a small area unit to a larger one, due to less information loss as the scale changes. In contrast, sensors with coarser resolution, such as ETM+, showed that most of the metrics are less dependent on the scale because the value of the determinant coefficient are lower than other sensors. This may indicate that due to information loss, the value of metrics from satellite data with coarser resolution is not suitable for investigating the landscape pattern, especially in areas where various types of landscape elements are mixed together in a complicated mosaic pattern. Some natural phenomena may thus be incorrectly interpreted if inappropriate data is used. It is therefore essential for researchers to choose a satellite sensor with appropriate resolution based on the goals for the project and a certain type of the study area.

The Yatsu valley environment researched here is typical of the southern Kanto Region. In this highly developed and heavily populated area the traditional rural landscape usually coexists with suburban residential or commercial development (Takeuchi et al 2003). Quick, efficient monitoring of changes in this landscape is thus essential for preserving a delicate balance between natural habitats and urban lifestyles.

Finally, this study has systematically investigated how landscape metrics respond to changing grain size among various resolution of satellite data. Although our results showed that changing scale (grain size) had significant effects on the metrics, how differences of scale relate to spatial heterogeneity between different satellite data also has to be numerically quantified. In addition, Turner et al (1989a) have noted that the development of methods that will preserve information across scales or quantify the loss of information with changing scales is a critical task. A future goal of this research is thus to construct a statistical model to quantify the scaling relations and detect the break point where landscape pattern may start to change fundamentally using various resolution satellites. This will involve not only focusing on grain size but examining how landscape pattern characteristics respond to changing extent and various types of study area as well. 


\section{ACKNOWLEDGMENTS}

This research was supported, in part, by the MEXT Strategic Research Infrastructure Formation Project "Research project for sustainable development of economic and social structure dependent on the environment of the eastern coast of Asia (TUIS)"; and by a grant-in-aid for scientific research A (No. 20241009) from MEXT Japan. We would also like to thank Dr. Kevin Short, Dr. JongGeol Park and Mr. Kazuyuki Takahashi for their help in data preparation and editing.

\section{REFERENCES}

Allen, T.F.H., Starr, T.B. (1982). Hierarchy: Perspectives for ecological complexity. The University of Chicago Press, Chicago.

Bain, D.J., Brush, G.S. (2004). Placing the pieces: Reconstructing the original property mosaic in a warrant and patent watershed. Landsc Ecol, 19(8): 843-856.

Benson, B.J., Mackenzie, M.D. (1995). Effects of sensor spatial resolution on landscape structure parameters. Landsc Ecol, 10(2):113-120.

Brown, J.H., West, G.B. (2000). Scaling in Biology. Oxford University Press, New York.

Fahrig, L., Merriam, G. (1985). Habitat patch connectivity and population survival. Ecology, 66(6):1762-1768.

Leitão, A.B., Miller, J., Ahern, J. \& Mcgarigal, K. (2006). Measuring landscapes: A Planner's Handbook. Island Press, Washington DC.

Leivin, S.A. (1992). The problem of pattern and scale in ecology. Ecology, 73(6):19431983.

Liu, H., Weng, Q. (2009). Scaling effect on the relationship between landscape pattern and land surface temperature: A case study of Indianapolis United States. Photog Eng. and Remote Sens., 75(3): 291-304.

Mcalpine, C.A., Eyre, T.J. (2002). Testing landscape metrics as indicators of habitat loss and fragmentation in continuous eucalpt forest (Queensland, Australia). Landsc. Ecol., 17(8): 711-728.

Mcgarigal, K., Cushman, S.A., Neel, M.C. \& Ene, E. (2002). FRAGSTATS: spatial pattern analysis program for categorical maps. Computer software program. Amherst, MA: University of Massachusetts. Retrieved 2005-05-01, from http://www.umass.edu/landeco/ research/fragstats./fragstats. html

Moody, A., Woodcock, C.E. (1995). The influence of scale and the spatial characteristic of landscape on land-cover mapping using remote sensing. Landsc. Ecol., 10(6): 363-379.

Neel, M.C., Mcgarigal, K. \& Cushman, S.A. (2004). Behavior of class-level landscape metrics across gradients of class aggregation and area. Landsc. Ecol., 19(2): 435-455.

Ouattrochi, D.A., Goodchild, M.F. (1997). Scale in Remote Sensing and GIS. CRC Press LLC, Florida.

Riitters, K., Wickham, J., O'neil, R., Jones, B. \& Smith, E. (2000). Global-scale patterns of forest fragmentation. Conservation Ecol., 4: 27-56.

Sakura City (2006). Principles of Yatsu environmental conservation in Sakura city. Retrieved 2009-02-15, from http://www.city.sakura.lg.jp/012543000_kankyohozen /kan_sei/yatukank you/pdffinalyatsusisinn.pdf 
Saura, S. (2004). Effects of remote sensor spatial resolution and data aggregation on selected fragmentation indices. Landsc. Ecol., 19(2): 197-209.

Schneider, D.C. (2001). Spatial allometry. In Gardner, R.H., Kemp, W.M., Kennedy, V.S. \& Petersen, J.E., (Eds.): Scaling Relations in Experimental Ecology. pp 113-15. Columbia University Press, New York,

Takeuchi, K., Brown, R.D., Washitani, I., Tsunekawa, A. \& Yokohari, M. (2003). SATOYAMA: The traditional rural landscape of Japan. Springer Verlag, Tokyo.

Tischendorf, L. (2001). Can landscape indices predict ecological processes consistently? Landsc Ecol, 16(3): 235-254.

Turner, M.G., O’neil, R.V., Gardner, R.H. \& Milne, B.T. (1989a). Effects of changing spatial scale on the analysis of landscape pattern. Landsc Ecol, 3(3-4):153-162.

Wu, J.G., Jelinski, D.E., Luck, M. \& ZTeller, P.T. (2000). Multiscale analysis of landscape heterogeneity: scale variance and pattern metrics. Geographical Infromation Science 6: 619.

Wu, J.G. (2004). Effects of changing scale on landscape pattern analysis: scaling relations. Landsc Ecol, 19(2): 125-138.

Wu, J.G. (2006). Scale and scaling: a cross-disciplinary perspective. In Wu, J.G., Hobbs R., (Eds): Key topics in landscape ecology. pp 118. Cambridge University Press, Cambridge, UK,

Zhu, M., Jiang, N., Li, J., Xu, J. \& Fan, Y. (2006). The effects of sensor spatial resolution and changing grain size on fragmentation indices in urban landscape. J. of Remote Sens., 27(21): 4791-4805. 